\title{
Chemical Compositions of Lonchocarpus cyanescens Benth., (Fabaceae)—Case Study of Its Volatile Oils, and Two Triterpenoids
}

\author{
Dorcas Olufunke Moronkola*, Ibrahim Adebayo Oladosu \\ Department of Chemistry, University of Ibadan, Ibadan, Nigeria. \\ Email: *funkemoronkola@yahoo.com
}

Received April $5^{\text {th }}, 2013$; revised May $6^{\text {th }}, 2013$; accepted June $7^{\text {th }}, 2013$

Copyright (C 2013 Dorcas Olufunke Moronkola, Ibrahim Adebayo Oladosu. This is an open access article distributed under the Creative Commons Attribution License, which permits unrestricted use, distribution, and reproduction in any medium, provided the original work is properly cited.

\begin{abstract}
Leaf and stem essential oils of Lonchocarpus cyanescens Benth., (Fabaceae) were obtained by hydro-distillation, using all-glass apparatus adapted to British Pharmacopeia specifications with yields of $0.03 \%$ and $0.17 \%$ respectively. The oils were investigated by GC and GC-MS analyses. Results show seven compounds were responsible for $90.4 \%$ of leaf; eleven compounds responsible for $97.6 \%$ of stem volatile oils. Phytol $(62.5 \%)$ and hexadecanoic acid $(12.4 \%)$ dominate the leaf oil; octadecenoic (24.1\%) and hexadecanoic acids (17.2\%) are predominant in the stem oil. Phytochemical screening of stem, leaf, and root methanol extracts of Lonchocarpus cyanescens reveal presence of following seven classes of metabolites: saponin, tannin, steroid, terpenoid, cardiac glycosides, phlobatannins and flavonoids. Partitioning of methanol extract from dried leaf of it with ethylacetate gave fraction, which was chromatographed using gradient elution. TLC with high Rf was used in monitoring elution. Two white crystalline solids eluted at $5 \%$ and $10 \%$ ethylethanoate in hexane, were re-crystallized and characterized. They were subjected to Infra-Red spectra, mass spectrometry (ESI technique), ${ }^{1} \mathrm{H}$ and ${ }^{13} \mathrm{C}$-NMR analyses, which confirmed they are triterpenoids. Above mentioned metabolites may be responsible for literature acclaimed bio-activities L. cyanescens display [anti-inflammatory, anti-arthritic, anti-microbial effects]. This paper presents details of above results which are new in literature.
\end{abstract}

Keywords: Lonchocarpus cyanescens; Fabaceae; Antimalaria; Phytochemistry; Essential Oils; GC, GC-MS, HPLC, IR, ${ }^{1} \mathrm{H}$ and ${ }^{13} \mathrm{C}-\mathrm{NMR}$

\section{Introduction}

Lonchocarpus cyanescens Benth., also known as Philenoptera cyanescens (Schumach. \& Thonn.) (Leguminosae-Papilionoideae, Fabaceae) is a deciduous scan dent shrub [1-3]. The plant has alternate leaves, flat fruits which are $1-5$ seeded, oblong pod pointed at both ends [3-5]. The aerial parts yield an indigo, which is a useful colourant for cloth dyeing [adire/ gara] in West Africa since ancient times [6]. Traditionally, woven cloth known as "country cloth" dyed with "gara" (using both synthetic and natural dyes) is found in many types of textiles used by chiefs for ceremonial dresses, bridal dowry, burial clothes, court fines and gifts to important visitors. Source of this dye is the "gara" leaf obtained from $L$. cyanescens [7-9]. Industrially, many people trade "gara": dried $L$.

\footnotetext{
"Corresponding author.
}

cyanescens is exported from Liberia and West African countries to Europe, United States, United Kingdom and many African countries [2,7-9].

The plant is utilized in traditional medicine. In Senegal, the leaves are used as a condiment eaten with couscous. L. cyanescens leaves and roots are applied as a poultice to treat skin diseases and ulcers; in Sierra Leone and Guinea Bissau, leaves and roots have been considered as a possible cure for leprosy; in Ghana, it is believed that the roots are more effective. Leaves are used as laxative. In Benin, leaf sap is drunk against intestinal disorders and dysentery. A decoction of leafy twigs and roots is given to women during or after childbirth and is also taken as an aphrodisiac. In Nigeria, this decoction is used to treat arthritic conditions, venereal diseases and diarrhea. Ground root is applied to yaws and washing with water containing powdered root helps to cure sores $[5$, 


\section{$8,10,11]$.}

L. cyanescens leaves have indoxyl which yields indigotin contained in the indigo dyestuff. Oleanane derivatives and glycyrrhetinic acid are responsible for the antiinflammatory properties and relief of peptic ulcers observed in $L$. cyanescens [2,12-14]. The triterpenes act against arthritis $[2,11,12,15,16]$. These natural products are also responsible for the taste effects utilized in flavoring [17].

Bioactivity effects of Lonchocarpus cyanescens have been demonstrated in its anti-inflammatory, anti-arthritic and its relief on ulcer. It has some additional pharmacological properties including antiviral, antifungal, anti-protozoal, and antibacterial activities. The anti-inflammatory activity of $L$. cyanescens has been confirmed using animal tests and is attributed to the presence of oleanane derivatives and glycyrrhetinic acid [pentacyclic triterpenoids of beta-amyrin type, easily obtained from hydrolysis of glycyrrhizic acid]. It also has antitussive properties, effective as expectorant, treatment of ulcer, and flavoring for masking bitter taste of drugs like quinine. The acid in ulcer treatment, inhibits the enzymes that metabolize the prostaglandins, $\mathrm{PGE}_{2 \mathrm{a}}$ to their inactive metabolites. This increases the level of prostaglandins in digestive system. These prostaglandins inhibit gastric secretion but stimulate pancreatic secretion and mucous secretion in the intestines. This may be the reason why glycyrrhetinic acid is said to relieve peptic ulcers $[2,12,15,17]$. A triterpene component of the plant has been found active against arthritis $[2,12,13]$. The plant is an active anti-arthritic remedy utilized with 3 other plants in Igbo tribal ethnomedicine [11].

Adewuyi et al. [18] reported in their studies on molecular speciation of the triacylglycerol, that seeds oils of $L$. cyanescens and $L$. sericeus were rich in $\mathrm{K}, \mathrm{Na}$ and $\mathrm{Fe}$. Their investigation revealed that linolenic and oleic acids are its dominant fatty acids with neutral lipids. GC-MS analyses of the seed oil showed phytol, sterols, beta-tocopherol and hydrocarbons are in the unsaponifiable matters of the oils; while HPLC showed presence of glycolipids [monogalactosyldiacylglycerol, digalactosyldiacylglycerol, digalactosylmonoacylglycerol and monogalactosylmonoacylglycerol].

We have identified more promising families of Nigerian plants from our collations of standardized questionnaires on anti-malaria herbs utilized in South-western Nigeria ethno-medicine comprising of Ogun, Oyo and Lagos states. Results of our recent studies revealed forty plants were utilized as anti-malaria herb [1]. We report our studies on volatile and phytochemical metabolites of one of them, a Fabaceae-Lonchocarpus cyanescens leaf, stem and root.

\section{Material and Methods}

\subsection{Plant Material}

The whole shrub of Lonchocarpus cyanescens were collected from Ago-Iwoye, Ogun-State, Nigeria for extraction of its volatile oils. Plant was authenticated at the Herbarium, Department of Botany, University of Ibadan, Ibadan, where voucher samples were deposited and signed certificate of identification was obtained [Prof Ayodele and Mr Donatus O. Esimekhuai]. Dr Soladoye M. O. (Plant taxonomists, OOU, Ago-Iwoye) also confirmed the plant. More plant samples for extractions were obtained from a farmland in the University of Ibadan Campus, Nigeria and identified by Dr. L. A. Adebisi of Department of Forest Resources Management, University of Ibadan.

\subsection{Extractions and Phytochemical Screening of Classes of Metabolites}

For essential oils' extractions, the plant was separated into leaf and stem parts. $500 \mathrm{~g}$ each of leaf and stem were crushed and hydro-distilled for $2.5 \mathrm{~h}$ in an all glass Clevenger-type apparatus designed to British Pharmacopeia specifications, with very small quantity of distilled nhexane $(0.5 \mathrm{ml})$, which was removed afterwards and the oils refrigerated. The essential oils were procured in $0.03 \%$ and $0.17 \%$ yields respectively. Each of the oils had distinct characteristic pleasant smell.

Leaf, stem and root cold methanol extracts of Lonchocarpus cyanescens were fractionated using distilled hexane to get methanol and hexane fractions. The leaf residue and stem interface were also obtained as fractions. Fractions were subjected to phytochemical analysis. Standard methods such as N. Lata and V. Dubey (2010) [19] were used in establishing classes of secondary metabolites present in each fraction.

\subsection{More Extractions and Isolations}

More leaf of $L$. cyanescens $(1.5 \mathrm{~kg})$ was dried and exhaustively extracted using cold methanol. The extract was concentrated to give dark green solid $(10.8 \mathrm{~g})$. Methanol extract $(10 \mathrm{~g})$ was further partitioned between aqueous methanol and ethylacetate to give the ethylacetate fraction. The ethylacetate fraction $(2 \mathrm{~g})$ was chromatographed on silica gel column eluting with increasing gradient of n-hexane: ethyl acetate and ethyl acetate: methanol to give seventy $100 \mathrm{ml}$ fractions. Similar fractions as determined by TLC were pooled together giving 10 combined fractions. Fractions 3 and 4 eluted with 5\% and $10 \%$ ethyl acetate in hexane were subjected to reversed phase HPLC separation using C-18 column and afforded white crystals purified by recrystallization in 
hexane to give $1\left(12 \mathrm{mg}, \mathrm{t}_{\mathrm{R}}=4.2 \mathrm{~min}\right)$ and $\underline{2}\left(20 \mathrm{mg}, \mathrm{t}_{\mathrm{R}}=\right.$ $3.2 \mathrm{~min})$.

\subsection{General Experimental Procedure}

Melting points were measured on a Gallenkamp melting point apparatus. Infra-Red spectra were measured in $\mathrm{KBr}$ on a Nicolet Avalar 320 FT-IR spectrometer. Reversed phase HPLC separation was carried out using C-18 column on an Agilent model 1100, $25 \times 250 \mathrm{~mm}, 5 \mathrm{~mm}$ particle size with a flow rate of $4.0 \mathrm{ml} \cdot \mathrm{min}^{-1}$ and monitored at $210-290 \mathrm{~nm}$. Mass spectrometry was obtained by ESI technique and NMR spectra $\left({ }^{1} \mathrm{H},{ }^{13} \mathrm{C}\right)$ were determined on a Bruker WP 200SY spectrometer (500 $\mathrm{MHz}$ for ${ }^{1} \mathrm{H}$ and $125 \mathrm{MHz}$ for ${ }^{13} \mathrm{C}$ ) in dimethylsulphoxide and deuteromethanol. Thin layer chromatographic separations were carried out on Merck precoated silica gel sheets $\left(60 \mathrm{~F}_{254}\right) 0.25 \mathrm{~mm}$ thickness and spots were viewed by spraying with conc. $\mathrm{H}_{2} \mathrm{SO}_{4} /$ Vanillin mixture with heating. Glass column of varying sizes (depending on weight of extract) and silica gel (70 - 230 mesh) were used for open column chromatography.

Leaf and stem essential oils were subjected to GC analyses on GC-2010[AOC-20i] gas chromatograph. Column oven temperature was $60^{\circ} \mathrm{C}$, injection temperature of $250^{\circ} \mathrm{C}$, split injection mode, at $100.2 \mathrm{kPa}$; column flow of $1.61 \mathrm{ml} / \mathrm{min} ; 1.0$ split ratio; oven temperature programming was $60^{\circ} \mathrm{C}$ (for $5 \mathrm{~min}$ ), and at the rate of $5^{\circ} /$ min till $140^{\circ} \mathrm{C}, 15^{\circ} / \mathrm{min}$ till $280^{\circ} \mathrm{C}$.

The GC-MS analyses were performed on GC-MS QP 2010 Plus. Ion source and interface temperature $250^{\circ} \mathrm{C}$; solvent cut time $2.5 \mathrm{~min}$; with relative detector gain mode and threshold 3000; scan MS ACQ mode; detector FTD; mass range of $\mathrm{m} / \mathrm{z} 40$ - 400 .

Identification of the essential oil components were based on their retention indices (determined with reference to homologous series of n-alkanes), along with comparison of their mass spectral fragmentation patterns by computer matching against in-built data and commercials such as Joulain and Koenig (1998), Adams (1995), and Massada (1976) Libraries, as well as in-house "Başer Library of Essential Oil Constituents" built up by genuine compounds and components of known oils [20-22].

\section{Results and Discussion}

\subsection{Gas Chromatography-Mass Spectrometric [GC-MS] Investigations of the Leaf and Stem Essential Oils}

Volatile oils from leaf (L) and stem bark (B) were obtained by hydro-distillation, using an all-glass apparatus adapted to British Pharmacopeia specifications and gave good yields of $0.03 \%$ and $0.17 \%$ respectively. The oils were analyzed using GC-MS (see Figures 1 and 2 for chromatograms). Seven prominent compounds in leaf make up $90.4 \%$ of it, while eleven most abundant compounds in stem are responsible for $97.6 \%$ of the oil. Phytol (62.5\%) and hexadecanoic acid (12.4\%) dominate the leaf oil (Table 1); while octadecenoic (24.1\%) and hexadecanoic acids are predominant in the stem oil (Table 2). Alcohols (64.1\%) dominate the leaf oil, while acids $(49.6 \%)$ are predominant in stem. The two oils contain hydrocarbons [L 6.2\%; B 10.0\%], acids [L 12.4\%; B

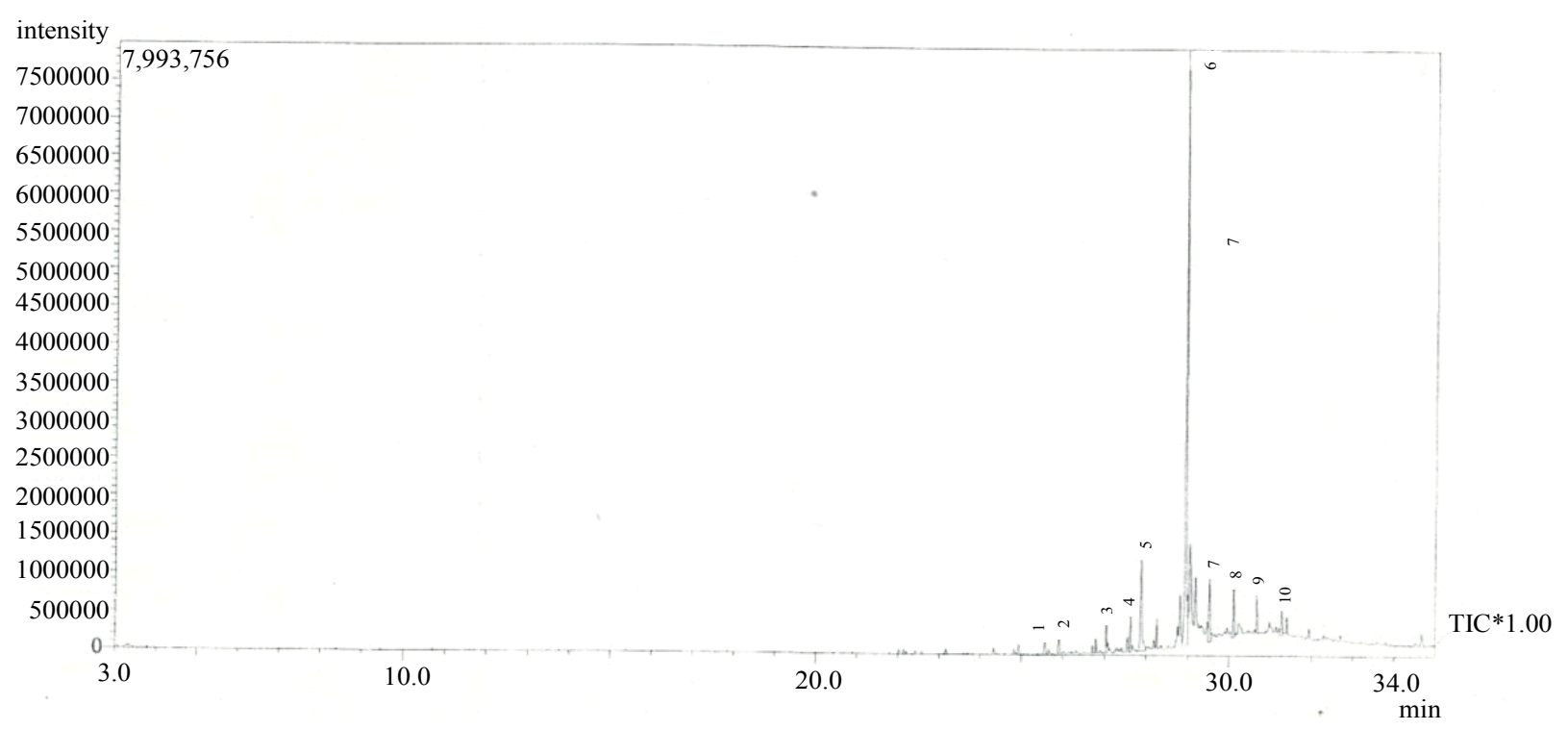

Figure 1. Gas chromatogram of the leaf essential oil of Lonchocarpus cyanescens using GC-2010 [AOC-20i] chromatograph. [Column $60^{\circ} \mathrm{C}$, injection temp. $250^{\circ} \mathrm{C}$, split injection mode at $100.2 \mathrm{kPa}$; flow $1.61 \mathrm{ml} / \mathrm{min}$; 1.0 split ratio; oven temperature programming is $60^{\circ} \mathrm{C}$ (for $5 \mathrm{mins}$ ), and at the rate of $5^{\circ} / \mathrm{min}$ till $140^{\circ} \mathrm{C}, 15^{\circ} / \mathrm{min}$ till $280^{\circ} \mathrm{C}$ [For peak numbers refer to Table 1 ]. 


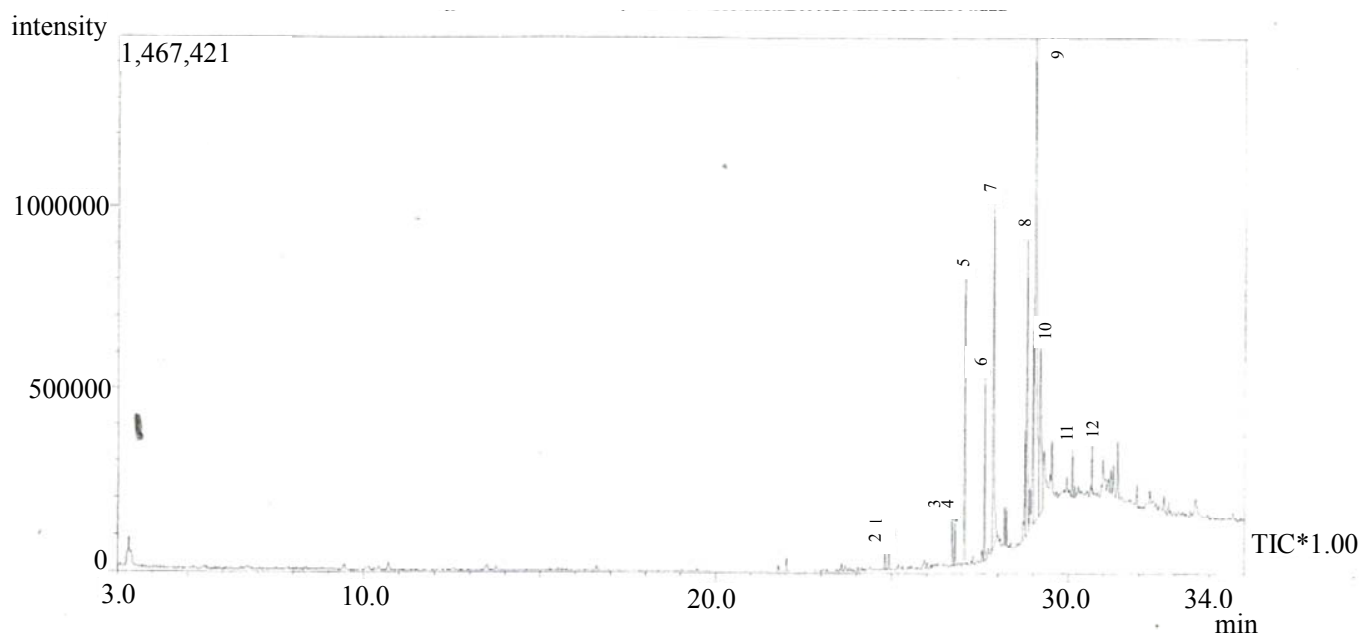

Figure 2. Gas chromatogram of the stem essential oil of Lonchocarpus cyanescens using GC-2010 [AOC-20i] chromatograph. [Column $60^{\circ} \mathrm{C}$, injection temp. $250^{\circ} \mathrm{C}$, split injection mode at $100.2 \mathrm{kPa}$; flow $1.61 \mathrm{ml} / \mathrm{min}$; 1.0 split ratio; oven temperature programming is $60^{\circ} \mathrm{C}$ (for $5 \mathrm{~min}$ ), and at the rate of $5^{\circ} / \mathrm{min}$ till $140^{\circ} \mathrm{C}, 15^{\circ} / \mathrm{min}$ till $280^{\circ} \mathrm{C}$ [For peak numbers refer to Table 2 ].

Table 1. Chemical composition of the essential oil of Lonchocarpus cyanescens leaf.

\begin{tabular}{cccccc}
\hline Peak No $^{\mathbf{a}}$ & MS [Base peak + most abundant peaks] $^{\mathbf{b}}$ & Identified compound $^{\mathbf{c}}$ & \%TIC $^{\mathbf{d}}$ & Retention time [min] $^{\mathbf{e}}$ & Calculated RI $^{\mathbf{f}}$ \\
\hline 1 & $69,83,55,97,70,43$, & 1-tetradecanol & 1.6 & 25.57 & 2385 \\
2 & $82,57,43,41,55,67,69,81,96$, & Pentadecanal & 1.7 & 25.91 & 2393 \\
3 & $43,58,71,57,59,85$, & $6,10,14$-trimethyl-2pentadecanone & 2.8 & 27.05 & 2421 \\
4 & $74,87,43,55,41,69$, & Methylhexadecanoate & 3.2 & 27.63 & 2748 \\
5 & $73,60,43,57,55,41$, & Hexadecanoic acid & 12.4 & 27.88 & 2754 \\
6 & $71,81,69,95,57,55,123$, & Phytol & 62.5 & 28.95 & 2781 \\
7 & $57,71,85,43,99,41,113$, & Heneicosane & 6.2 & 29.52 & 2795 \\
8 & $57,71,85,43,99,113,41$, & u.i. ${ }^{g}$ & 4.1 & 30.1 & 2810 \\
9 & $57,71,85,43,99,113,41$, & u.i. ${ }^{g}$ & 2.9 & 30.67 & 2824 \\
10 & $57,71,85,43,99,113,41$, & u.i. ${ }^{g}$ & 2.5 & 31.27 & 2839 \\
\hline
\end{tabular}

${ }^{a}$ According to the rention time from $\mathrm{GC} ;{ }^{\mathbf{b}}[\mathrm{m} / \mathrm{e}]$ values of base peak 1 st stated, and other most prominent ions; ${ }^{\mathrm{c}}$ see identification of components; ${ }^{\mathrm{d}}$ Total ion concentration in \%; ${ }^{\mathrm{e}}$ Retention time in minutes; ${ }^{\mathrm{f}}$ Retention Index determined with reference to homologous series of $\mathrm{n}$-alkanes; ${ }^{\mathrm{g}}$ unidentified component.

Table 2. Chemical composition of the essential oil of Lonchocarpus cyanescens stem.

\begin{tabular}{cccccc}
\hline Peak No $^{\mathbf{a}}$ & MS [Base peak + most abundant peaks] $^{\mathbf{b}}$ & Identified compound $^{\mathbf{r}}$ & \%TIC $^{\mathbf{d}}$ & Retention time [min] $^{\mathbf{e}}$ & Calculated RI $^{\mathbf{f}}$ \\
\hline 1 & $83,97,55,56,70,105,69$, & 1 -tridecene & 1.6 & 24.82 & 2367 \\
2 & $57,71,43,85,55,41,99$, & $2,6,10,15$-tetramethylheptadecane & 1.5 & 24.93 & 2370 \\
3 & $83,97,55,57,69,70,43,56,71$, & 1 -nonadecene & 2.4 & 26.72 & 2413 \\
4 & $57,71,85,43,41,105,99,69$, & Nonadecane & 2.1 & 26.79 & 2415 \\
5 & $57,149,41,104,76,223,56,93$, & Diisopropylphthalate & 14.2 & 27.06 & 2421 \\
6 & $74,87,43,55,41,69,75$, & Methylhexadecanoate & 9.1 & 27.63 & 2748 \\
7 & $73,60,43,57,55,41,71,69$, & Hexadecanoic acid & 17.2 & 27.87 & 2754 \\
8 & $55,69,74,83,97,41,96,84$, & Methyl 9-octadecenoate & 14.7 & 28.81 & 2778 \\
9 & $55,69,83,41,97,67,81$, & Octadecenoic acid & 24.1 & 29.04 & 2783 \\
10 & $73,55,43,57,41,60,69$, & Octadecanoic acid & 8.3 & 29.19 & 279 \\
11 & $57,71,85,43,99,113,41$, & Heneicosane & 2.4 & 30.1 & 2810 \\
12 & $57,71,85,43,99,113,55,41$, & u.i. ${ }^{g}$ & 2.2 & 30.66 & 2824 \\
\hline
\end{tabular}

${ }^{\mathrm{a}}$ According to the rention time from GC; ${ }^{\mathbf{b}}[\mathrm{m} / \mathrm{e}]$ values of base peak 1 st stated, and other most prominent ions; ${ }^{\mathbf{s}}$ see identification of components; ${ }^{\mathbf{d}}$ Total ion concentration in \%; ${ }^{\mathrm{e}}$ Retention time in minutes; ${ }^{\mathrm{f}}$ Retention Index determined with reference to homologous series of $\mathrm{n}$-alkanes; ${ }^{\mathrm{g}}$ unidentified component. 
49.6\%] and esters [L 3.2\%; B 38.0\%]. Other compositions in leaf are ketone $(2.8 \%)$ and aldehyde $(1.7 \%)$ (see Table 3).

\subsection{Phytochemical Screenings to Obtain Classes of Metabolites in Leaf, Stem and Root Extracts}

Phytochemical screenings indicated extracts contain seven important classes of secondary metabolites which are saponin, tannin, steroid, terpenoid, cardiac glycoside, phlobatannins and flavonoids (Table 4).

\subsection{Two Compounds Isolated from Ethylacetate Extract}

Partitioning of methanol extract of dried leaf of Lonchocarpus cyanescens with ethylacetate gave the ethylacetate extract, which was chromatographed using gradient elution. Two white crystalline solids were eluted at 5\% and $10 \%$ ethylethanoate in hexane. Each was loaded on reversed phase HPLC, and was further purified by recrystallization. They were subjected to Infra-Red spectra, mass spectrometry (ESI technique), ${ }^{1} \mathrm{H}-\mathrm{NMR}$ and ${ }^{13} \mathrm{C}$ NMR analyses, which showed they are triterpenoids (Table 5). Results of ${ }^{1} \mathrm{H}$-NMR and ${ }^{13} \mathrm{C}-\mathrm{NMR}$ indicate the compounds 1 and 2 have the following structures

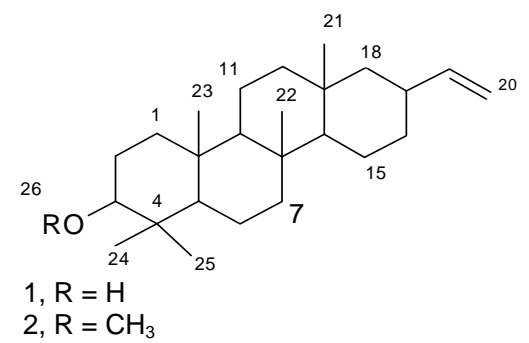

\section{Conclusion}

Volatile oils from leaf (L) and stem (B) were analyzed using GC and GC-MS. Seven compounds in leaf made up $90.4 \%$ of it, while eleven compounds in stem were responsible for $97.6 \%$ of the oil. Phytol (62.5\%) and hexadecanoic acid (12.4\%) dominate the leaf oil [Table 1]; while octadecenoic (24.1\%) and hexadecanoic acids are predominant in the stem oil [Table 2]. Alcohols (64.1\%) dominate the leaf oil, while acids (49.6\%) are predominant in stem. The two oils contain hydrocarbons [L 6.2\%; B 10.0\%], acids [L 12.4\%; B 49.6\%] and esters [L 3.2\%; B 38.0\%]. Other compositions in leaf are ketone $(2.8 \%)$ and aldehyde $(1.7 \%)$ (Table 3). Cold soaked methanol extract which was defattened with hexane, and volatile oils of leaf (L), stem (B) and root (R) of Lonchocarpus cyanescens prominently utilized as antimalaria in Nigerian ethno-medicine were screened. Phytochemical screenings indicated extracts contain seven important classes of secondary metabolites which are saponin, tannin, steroid, terpenoid, cardiacglycoside, phlobatannins and flavonoids (Table 4). Phytochemical analyses of the leaf ethylacetate extract yielded two triterpenoids [ 1 and 2] (see Table 5). We suggest these reported metabolites are responsible for the acclaimed bio-activities $L$. cyanescens is known to have [anti-inflammatory, anti-arthritic, anti-microbial, anti-tussive and anti-ulcer effects]. This is reported for the first time. Work is ongoing on other aspects of $L$. cyanescens.

\section{Acknowledgements}

We acknowledge the assistance of 1) DOM students [Osikoya OF; Nwabueze CC \& Quadri HB] in collections, isolations and general laboratory work on plant samples; 2) Dr Kunle of NIPRD, Abuja for supervising

Table 3. Comparison between the chemical compositions of leaf and stem volatile oils.

\begin{tabular}{ccccccc}
\hline$\%$ & Alcohols & Acids & Hydrocarbons & Esters & Ketone & Aldehyde \\
\hline Leaf & 64.1 & 12.4 & 6.2 & 3.2 & 2.8 & 1.7 \\
Stem & - & 49.6 & 10 & 38 & - & - \\
\hline
\end{tabular}

Table 4. Classes of phytochemical compounds identified in Lonchocarpus cyanescens [fabaceae] stem, leaf and root methanol and hexane fractions.

\begin{tabular}{ccc}
\hline Extract/Fraction & Methanol & Hexane \\
\hline Leaf & tannin; phlobatannin & steroid \\
Stem & Saponin & tannin; cardiac glycosides \\
Root & Phlobatannins & tannin; phlobatannin \\
Leaf residue & Flavonoid & \\
Stem interface & terpenoid; cardiac glycosides & \\
\hline
\end{tabular}


Table 5. ${ }^{1} \mathrm{H}$-NMR and ${ }^{13} \mathrm{C}-\mathrm{NMR}$ assignment of compounds $\underline{1}$ and $\underline{2}$.

\begin{tabular}{|c|c|c|c|}
\hline Carbon & $\delta^{13} \mathrm{C}-\mathrm{NMR}$ & Multiplicity & $\delta^{1} \mathrm{H}-\mathrm{NMR}$ \\
\hline 1 & 31.9 & $\mathrm{CH}_{2}$ & $1.50,1.40$ \\
\hline 2 & 29.4 & $\mathrm{CH}_{2}$ & $2.17,2.30$ \\
\hline 3 & 79.1 & $\mathrm{CH}$ & 3.18 \\
\hline 4 & 39.9 & $\mathrm{C}$ & - \\
\hline 5 & 47.2 & $\mathrm{CH}$ & 2.32 \\
\hline 6 & 20.9 & $\mathrm{CH}_{2}$ & $1.24,1.67$ \\
\hline 7 & 37.1 & $\mathrm{CH}_{2}$ & $1.32,1.45$ \\
\hline 8 & 39.8 & $\mathrm{C}$ & - \\
\hline 9 & 60.68 & $\mathrm{CH}$ & 2.34 \\
\hline 10 & 35.5 & $\mathrm{C}$ & - \\
\hline 11 & 18.2 & $\mathrm{CH}_{2}$ & $1.22,1.64$ \\
\hline 12 & 40.7 & $\mathrm{CH}_{2}$ & $1.46,1.36$ \\
\hline 13 & 34.2 & $\mathrm{C}$ & - \\
\hline 14 & 55.2 & $\mathrm{CH}$ & 2.36 \\
\hline 15 & 19.2 & $\mathrm{CH}_{2}$ & $1.17,1.61$ \\
\hline 16 & 33.8 & $\mathrm{CH}_{2}$ & $1.02,1.53$ \\
\hline 17 & 39.9 & $\mathrm{CH}$ & 2.36 \\
\hline 18 & 31.9 & $\mathrm{CH}_{2}$ & $1.64,2.38$ \\
\hline 19 & 109.3 & $\mathrm{CH}$ & 4.68 \\
\hline 20 & 150.9 & $\mathrm{CH}_{2}$ & $4.56,4.60$ \\
\hline 21 & 22.6 & $\mathrm{CH}_{3}$ & 0.96 \\
\hline 22 & 25 & $\mathrm{CH}_{3}$ & 0.89 \\
\hline 23 & 16.1 & $\mathrm{CH}_{3}$ & 0.85 \\
\hline 24 & 17.9 & $\mathrm{CH}_{3}$ & 0.93 \\
\hline 25 & 20.9 & $\mathrm{CH}_{3}$ & 1.02 \\
\hline $26[\underline{2}]$ & 56.7 & $\mathrm{CH}_{3}$ & 3.22 \\
\hline
\end{tabular}

running of the GC and GC-MS, which we paid for; 3) Mac-Akhatur Foundation for Dr I. A. Oladosu.

\section{REFERENCES}

[1] D. O. Moronkola, A. A. Adedeji, I. O. Oyewole, I. A. Ogunwande and I. A. Oladosu, "Survey and Accounts of Anti-Malaria Ethnomedicinal Herbs Used In South-Western Nigeria and Vector Repellant Activities of Their Volatile Oils," The African Network for Drugs and Diagnostics [ANDI], 2nd Stakeholders Meeting \& Conference, Medical Research Council [MRC], Cape Town, 4-7 October 2009.
[2] D. Cardon and P. C. M. Jarsen, "Philenoptera cyanescens (Schumach. \& Thonn.) Roberty," In: P. C. M. Jarsen and D. Cardon, Eds., PROTA 3: Dyes and Tannins/Colorants et Tannins, PROTA, Wageningen, 2005.

[3] B. D. Schrire, "A Synopsis of the Genus Philenoptera (Leguminosae millettieae) from Africa and Madagascar," Kew Bulletin, Vol. 55, No. 1, 2000, pp. 81-94. doi: $10.2307 / 4117762$

[4] H. M. Burkill, "Useful Plants of West Tropical Africa," Royal Botanic Gardens Kew, Vol. 3, 1985.

[5] F. R. Irvine, "Woody Plants of Ghana, with Special Reference to Their Uses," Oxford University Press, London, 1961, p. 868.

[6] A. G. Perkin and F. Thomas, "RSC Publishing Paper XC. -Indican, Part II," Journal of the Chemical Society, Transactions, Vol. 95, 1909, pp. 793-807. doi:10.1039/ct9099500793

[7] D. Cardon, "Le Monde des Teintures Naturelles," Belin, Paris, 2003, p. 586.

[8] S. Spencer, "Developing an Understanding of Science from the Sierra Leonean Traditional Gara Dyeing Process," Gender and Science and Technology Association Conference, GASAT 8, Ahmedabad, January 1996.

[9] C. Polakoff, "Into Indigo-African Textiles and Dyeing Techniques," Anchor Books, Garden City, 1980, p. 243.

[10] J. Jukema, N. Wulijarni-Soetjipto, R. H. Lemmens and J. W. Hildebrand, "Minor Dye and Tannin-Producing Plants," In: R. H. Lemmens and N. Wulijarni-Soetjipto, Eds., Plant Resources of South-East Asia No 3. Dye and Tannin Producing Plants, Pudoc, Wageningen, 1991, p. 132142.

[11] M. M. Iwu and B. N. Anyanwu, "Phytotherapeutic Profile of Nigerian Herbs, 1: Anti-Inflammatory and Anti-Arthritic Agents," Journal of Ethnopharmacology, Vol. 6, No. 3, 1982, pp. 263-274. doi:10.1016/0378-8741(82)90049-6

[12] M. M. Iwu, "Comparative Estimation of Glycyrrhetinic Acid Content of L. cyanescens and glycyrrhiza Roots," Journal of Pharmaceutical Science, Vol. 71, No. 12, 2006, pp. 1412-1413. doi:10.1002/jps.2600711227

[13] O. N. Ogbeide and M. Parvez, "A Simple Colorimetric Quantification of Flavonoids in the Flowers of L. cyanescens," Plant Foods for Human Nutrition, Vol. 41, No. 3, 1991, pp. 233-239. doi:10.1007/BF02196391

[14] R. Promsattha, R. B. Taylor, M. S. Tempesta and M. M. Iwu, "Chemical Studies on the Nigerian Plant $L$. cyanescens Benth. Application of Autocorrelated 2D-DQC Spectroscopy to Structure and C-13 Assignments of the Triterpenoid Lupeol," International Journal of Crude Drug Research, Vol. 25, 1987, pp. 221-224.

[15] K. C. Ndukwe, A. Lamikanra and I. N. Okeke, "Antibacterial Activity in Plants Used as Chewing Sticks in Africa," Prous Science Drugs of the Future, Vol. 29, No. 12, 2004, p. 1221. doi:10.1358/dof.2004.029.12.853766

[16] Sami Labs Ltd., Glycyrrhetinic Acid, GLABRIDIN, 2003.

[17] S. Ijichi and T. Seizo, "Molecular Design of Sweet Tasting Compounds Based on $\beta$-Amino-3 $\beta$-Deoxy-18 $\beta$-Gly- 
cyrrhetinic Acid: Amido Functionality Eliciting Tremendous Sweetness," Chemistry Letters, Vol. 34, 2005, p. 356. doi:10.1246/cl.2005.356

[18] A. Adewuyi, R. A. Oderinde, B. V. S. K. Rao and R. B. N. Prasad, "Chemical Composition and Molecular Speciation of the Triacylglycerol of the Oils of Lonchocarpus sericeus and Lonchocarpus cyanescens," Natural Product Research, Vol. 26, No. 20, 2012, pp. 1954-1956. doi:10.1080/14786419.2011.643311

[19] N. Lata and D. Venapani, "Preliminary Phytochemical Screening of Eichhornia crassipes: The World's Worst
Aquatic Weed," Journal of Pharmaceutical Research, Vol. 3, No. 6, 2010, pp. 1240-1242.

[20] D. Joulain and W. A. Koenig, "The Atlas of Spectral Data of Sesquiterpene Hydrocarbons," E-B Verlag, Hamburg, 1998.

[21] R. P. Adams, "Identification of Essential Oil Components by Gas Chromatography-Mass Spectroscopy," Allured Pub Corp, Carol Stream, 1995.

[22] Y. Massada, "Analysis of Essential Oils by Gas Chromatograph and Mass Spectrometry," Wiley \& Sons, New York, 1976. 